Pacific Journal of Mathematic 


\title{
POINTWISE BOUNDED APPROXIMATION BY FUNCTIONS SATISFYING A SIDE CONDITION
}

\author{
A. STRAY
}

In this paper necessary and sufficient conditions on a subset $S$ of the unit disc $D$ are given such that every bounded analytic function $f$ on $D$ is a pointwise limit of a sequence $\left\{f_{n}\right\}_{n=1}^{\infty}$ of uniformly continuous analytic functions on $D$ bounded by the sup norm of $f$ and in addition satisfying $\sup \left\{\left|f_{n}(z)\right|\right.$, $z \in S\} \leqq \sup \{|f(z)|, z \in S\}$ for all $n$.

Let $D=\{z:|z|<1\}$ denote the open unit disc and $T=\{z:|z|=1\}$ the unit circle. $H^{\infty}(D)$ denotes all bounded analytic functions on $D$ and $A(D)$ consists of all uniformly continuous $f$ in $H^{\infty}(D)$. For any $f \in H^{\circ}(D)$ and any subset $S$ of $D$ we put $\|f\|_{s}=\sup \{|f(z)|, z \in S\}$ and we set $\|f\|=\|f\|_{D}$.

A sequence $\left\{z_{n}\right\}_{n=1}^{\infty}$ in $D$ converging to $z \in T$ converges nontangentially to $z$ if for some constant $\lambda$ we have $\left|z-z_{n}\right| \leqq \lambda\left(1-\left|z_{n}\right|\right)$ for all $n$. If $f \in H^{\infty}(D)$ then Fatou's theorem [2, page 34] tells us that $f$ has a nontangential limit at almost every boundary point. Thus at almost every boundary point $\lim f\left(z_{n}\right)$ exists and is independent of the choice of sequence. If $f \in H^{\infty}(D)$ is known a.e. on $T$ we recapture its values in $D$ by the Cauchy or Poisson integral formula. We will therefore consider functions in $H^{\infty}(D)$ as defined in $D$ and a.e. on $T$.

A relatively closed subset $S$ of $D$ is called a Farrell set if for each $f \in H^{\infty}(D)$ there are $f_{n} \in A, n=1,2, \cdots$, converging pointwise to $f$ on $D$ with $\left\|f_{n}\right\| \leqq\|f\|$ and such that $\left\|f_{n}\right\|_{s} \leqq\|f\|_{s}$. This concept was introduced to us by Professor L. A. Rubel who also raised the question of describing such sets. The object here is to characterize Farrell sets in terms of their cluster points on $T$. The author is very grateful to Dr. A. M. Davie for valuable conversations on this subject.

First we observe that if $r z \in S$ whenever $0<r<1$ and $z \in S$, then $S$ is a Farrell set. Indeed, letting $f_{r}(z)=f(r z)(0<r<1)$, we have: $f_{r}(z) \rightarrow f(z)$ as $r \rightarrow 1$.

On the other hand, let $S=\left\{z_{n}\right\}_{n=1}^{\infty}$ where $\sum_{n}\left(1-\left|z_{n}\right|\right)<\infty$ and assume that the set of cluster points of $S$ on $T$ has positive linear measure. Then there are $f \in H^{\infty}(D)$ with $f=0$ on $S$, but $f \neq 0$, while if $f \in A(D)$ and $f=0$ on $S$ we must have $f \equiv 0$. The set of cluster points of $S$ on $T$ which are not nontangential limits of sequences from $S$ is here too large. In fact we will prove the following.

THEOREM. A relatively closed subset $S$ of the open unit disc $D$ is 
a Farrell set if and only if the set $S_{1}$ of cluster points of $S$ on $T$ which are nontangential limits of sequences from $S$ has zero linear measure.

Proof. First assume $S_{1}$ has positive linear measure. Using ideas from [1] we construct a function $f \in H^{\infty}(D)$ which shows that $S$ is not a Farrell set. If $t>0$ and $z \in T$ we define

$$
\Delta(z, t)=\{w: 0<1-|w| \leqq t,|z-w| \leqq 2(1-|w|)\} .
$$

For $t>0$ we also define $E_{t}=\{z \in \bar{S} \cap T: \Delta(z, t) \cap S=\varnothing\}$.

Since $S_{1} \subseteq \bigcup_{t} E_{t}$ has positive measure, we can find for some $t_{0}$ a set $E=E_{t_{0}}$ of positive measure.

Let $u$ be the harmonic extension to $D$ of the function on $T$ which is zero on $E$ and -1 on $T \backslash E$. Define $f=\exp [u+i v]$ where $v$ is a harmonic conjugate to $u$ in $D$. Then $f \in H^{\infty}(D)$ and by the theorem of Fatou we have $|f|=1$ a.e. on $E$ and $|f|=e^{-1}$ a.e. on $T \backslash E$. In particular $\|f\|=1$.

We claim that $\|f\|_{s}<1$. Assume this proved. Let $\left\{f_{n}\right\}_{n=1}^{\infty} \subset$ $A(D),\left\|f_{n}\right\| \leqq 1$ and assume $f_{n}(z) \rightarrow f(z) z \in D$. We prove that $\left\|f_{n}\right\|_{S} \rightarrow 1$ which in turn will show that $S$ is not a Farrell set.

Given $\varepsilon>0$ it follows from Fatou's theorem that there exists $z \in D$ such that

$$
\begin{aligned}
|f(z)| & >1-\varepsilon \\
m_{z}(E) & >1-\varepsilon .
\end{aligned}
$$

Here $m_{z}$ denotes harmonic measure on $T$ w.r.t. $z$.

There exists a number $N$ such that

$$
\left|f_{n}(z)-f(z)\right|<\varepsilon \quad \text { if } n>N \text {. }
$$

By (1) and (3) we have $\left|f_{n}(z)\right|>1-2 \varepsilon$ if $n>N$.

But on the other hand we have

$$
\left|f_{n}(z)\right| \leqq \int_{E}\left|f_{n}\right| d m_{z}+\int_{T \backslash E}\left|f_{n}\right| d m_{z} \leqq\left\|f_{n}\right\|_{E}+\varepsilon
$$

so that $1 \geqq\left\|f_{n}\right\|_{S} \geqq\left\|f_{n}\right\|_{E} \geqq 1-3 \varepsilon$ if $n \geqq N$.

It remains to prove that $\|f\|_{S}<1$. Choose $z \in S$ such that $|z|>1-t_{0}$.

Define $J_{z}=\{w \in T:|w-z|<2(1-|z|)\}$. By a well-known estimate of harmonic measure there exists a constant $c \in(0,1)$ depending only on $t_{0}$ such that

$$
m_{z}\left(J_{z}\right) \geqq c .
$$

Since $z \in S$ we have $J_{z} \cap E=\varnothing$. 
By (4) we therefore have since $|f| \leqq 1$ a.e. on $E$ and $|f| \leqq e^{-1}$ a.e. on $T \backslash E$ :

$$
\begin{aligned}
|f(z)| & \leqq \int_{E}|f| d m_{z}+\int_{T \backslash E}|f| d m_{z} \leqq m_{z}(E)+\frac{1}{e} m_{z}(T \backslash E) \\
& \leqq 1-c+c e^{-1}<1-c 2^{-1} \quad \text { if } \quad z \in S .
\end{aligned}
$$

Since clearly $\sup \left\{|f(z)|:|z| \leqq 1-t_{0}\right\}<1$, the claim is proved.

Suppose now $S_{1}$ has zero linear measure.

We first consider the special case where $B=\bar{S} \cap T$ itself has zero measure.

Given $f \in H^{\infty}(D)$ we first choose functions $g_{n}$ continuous on $D \cup T \backslash B$ and analytic in $D$ such that $\left\|g_{n}\right\|_{D} \leqq\|f\|,\left\|g_{n}\right\|_{S} \leqq\|f\|_{S}$ and $g_{n}(z) \rightarrow f(z)$ if $z \in D$. (See [3] §1.)

We then choose $\left\{a_{n}\right\}_{n=1}^{\infty} \subset A(D)$ converging pointwise to 1 on $D$ such that $\left\|a_{n}\right\|=1$ and $a_{n}=0$ on $B$. See [2], p. 80 for a construction of the $a_{n}$ 's.

Define $f_{n}=0$ on $B$ and $f_{n}=a_{n} g_{n}$ in $D \backslash B$. Then $f_{n} \in A(D)$ and $\left\{f_{n}\right\}_{n=1}^{\infty}$ approximates $f$ as required.

Finally we consider the case where $B$ has positive linear measure.

Define $H(\theta, z)=\left(e^{i \theta}+z\right) /\left(e^{i \theta}-z\right)$ if $-\pi<\theta \leqq \pi$ and $z \in D$.

Choose $f \in H^{\infty}(D)$ with $\|f\|=1$. Let $\eta=\|f\|_{s}$. If $\eta=0$ it follows from Fatou's theorem and that $S_{1}$ has zero linear measure, that $|f|=0$ a.e. on $B$ which is impossible since $f \neq 0$ and $B$ has positive measure. Hence $\eta>0$.

We can factorize $f$ as $f=I \cdot F$ where $I$ and $F$ denotes the "inner" and "outer" part of $f$. [[2], Ch. 5.]

Here $F$ is given by

$$
F(z)=\exp \left[\frac{1}{2 \pi} \int_{-\pi}^{\pi} H(\theta, z) u(\theta) d \theta\right]
$$

and it follows from the hypothesis that $u \leqq 0$ a.e. on $T$ and $u \leqq \log \eta$ a.e. on $B$.

Fix a positive integer $n$. Let $u_{1}$ be a continuously differentiable function on $T$ and $V \supset B$ a set open in $T$ such that $u_{1} \leqq 0, u_{1} \leqq \log \eta$ on $V$ and with the following properties:

$$
\begin{gathered}
\int_{-\pi}^{\pi}\left|u(\theta)-u_{1}(\theta)\right| d \theta<\frac{1}{n} \\
\int_{T \backslash V}\left|H(\theta, z)\left(u(\theta)-u_{1}(\theta)\right)\right| d \theta<\frac{1}{n} \text { for all } z \in S .
\end{gathered}
$$

To obtain $u_{1}$ on $V$ one first defines $u_{1}$ in a neighborhood of $B$ such that $\int_{B}\left|u(\theta)-u_{1}(\theta)\right| d \theta<1 / 2 n$. This inequality will still hold if $B$ is 
replaced by some open set $V$ containing it if linear measure of $V \backslash B$ is small enough. But then it is easy to extend $u_{1}$ to $T$ so that (5) and (6) hold.

Since $u_{1} \leqq \log \eta$ on $V$ and $u_{1} \leqq 0$ there is a compact subset $K$ of $S$ such that

$$
\int u_{1} d m_{z} \leqq \log \left(\eta+\frac{1}{n}\right) \quad \text { if } \quad z \in S \backslash K .
$$

Let $A=\left\{z \in V: u(z) \leqq u_{1}(z)\right\}$ and $M$ be a compact subset of $A$. We choose a continuously differentiable function $a \leqq 0$ such that supp $a$ (the support of $a$ ) is contained in $V$ and we have

$$
\left|\int_{V} H(\theta, z)\left(u_{1}+a-u\right)(\theta) d \theta\right|<\frac{1}{n} \quad \text { if } \quad z \in K .
$$

If $a$ approximates $u-u_{1}$ sufficiently well on $M$ and if the linear measures of $A \backslash M$ and supp $a \backslash M$ are sufficiently small we can obtain that (5) and (6) still hold if we replace $u_{1}$ by $\left(u_{1}+a\right)$ there.

We define $g_{n}(z)=\exp \left[1 / 2 \pi \int_{-\pi}^{\pi}\left(H(\theta, z)\left(u_{1}+a\right)(\theta) d \theta\right], z \in D\right.$.

Since $u_{1}+a$ is smooth $g_{n} \in \vec{A}(D)$ and $\left\|g_{n}\right\| \leqq 1$ since $u_{1}+a \leqq 0$.

By (5), $\mathrm{g}_{n}(z) \rightarrow F(z)$ if $z \in D$. When $z \in S \backslash K$, (7) implies that $\left|g_{n}(z)_{1}\right| \leqq \eta+1 / n$ and if $z \in K$ we get from (6) and (8) that $\left|g_{n}(z)\right| \leqq \eta e^{1 / n}$.

Define now $h_{n}=(\eta /(\eta+3 / n)) g_{n}$ and $B_{n}(z)=I\left(z\left(1-n^{-1}\right)\right)$ if $z \in D$ and $n=1,2, \cdots$.

The sequence $f_{n}=B_{n} h_{n} n=1,2, \cdots$ approximates $f$ as required.

We have completed the proof that $S$ is a Farrell set if $S_{1}$ has zero linear measure and the proof also shows how to construct the functions $\left\{f_{n}\right\}$ given $f$ such that they satisfy the requirements given in the definition of a Farrell set.

If $S_{1}$ has zero linear measure and $B$ has positive linear measure there is a proof based on functional analysis showing that $S$ is a Farrell set. This proof is due to Dr. A. M. Davie. Since the proof is short and rather different from the one given above we would like to include it here.

So we assume $f \in H^{\infty}(D),|f|=1$ and $\|f\|_{s}=\eta>0$.

Let $N=\left\{f \in C(\bar{D})\|f\|_{s} \leqq \eta\right.$ and $\left.\|f\| \leqq 1\right\}$. We have to show that $f$ is in the closure of $N \cap A(D)$ in the topology of uniform convergence on compact subsets of $D$.

By the separation theorem and Riez representation theorem it is sufficient to prove that $|\mu(f)| \leqq 1$ whenever $\mu$ is a regular complex Borel measure with compact support in $D$ such that $|\mu(h)| \leqq 1$ for all $h \in N \cap A(D)$. $\quad(N \cap A(D)$ is a convex set in the space of all continuous functions in $D$, with the topology of uniform convergence on compact subsets of $D$ and the dual space is the space of regular 
complex Borel measures with compact support in $D$.)

$N$ is the unit ball w.r.t. some norm on $C(\bar{D})$ which is equivalent to sup norm on $\bar{D}$ since $\eta>0$.

Hence we can extend the functional $g \rightarrow \mu(g)$ from $A(D)$ to $C(\bar{D})$ and represent it by a measure $\nu$ on $\bar{D}$ such that $|\nu(g)| \leqq 1$ for all $g \in N$.

But the last fact implies

$$
(I):|\nu|(\bar{D} \mid \bar{S})+\eta|\nu| \bar{S} \leqq 1
$$

where $|\nu|$ denotes the total variation of $\nu$.

We claim that $\nu(E)=0$ if $E \subset T$ has zero linear measure. To see this let $K \subset E$ be compact. Choose $\left\{a_{n}\right\}_{n=1}^{\infty} \subset A(D)$ such that $\left\|a_{n}\right\|=1$, $a_{n}=0$ on $K$, and $a_{n} \rightarrow 1$ on $\bar{D} \backslash K$. (The sequence $\left\{a_{n}\right\}$ mentioned in the previous proof will do.) Then $0=(\mu-\nu)\left(1-a_{n}\right) \rightarrow(\mu-\nu)(K)=\nu(K)$ by dominated convergence.

This means that $f$ is defined a.e. $\nu$ and if $\left\{f_{n}\right\} \subset A(D)$ converges pointwise to $f$ on $D$ and a.e. to $f$ on $T$ such that $\left\|f_{n}\right\| \leqq\|f\|$ we again have by dominated convergence that $0=\mu(f)-\nu(f)$. But $|f| \leqq 1$ a.e. $\nu$ and $|f| \leqq \eta$ a.e. $\nu$ on $S$ so $|\mu(f)|=|\nu(f)| \leqq 1$ by $(I)$.

\section{REFERENCES}

1. L. Brown, A. Shields, and K. Zeller, On absolutely convergent exponential sums, Trans. Amer. Math. Soc., 96 (1960), 162-183.

2. K. Hoffman, Banach Spaces of Analytic Functions, Prentice-Hall, Inc., Englewood Cliffs, N.J. 1962

3. A. Stray, Approximation and interpolation, Pacific. J. Math., 40 (1972), 463-475.

Received October 27, 1972 and in revised form February 20, 1973.

AGDER DISTRIKSHOGSKOLE

PostBoks 332

4600 KRIstiansand S.

NORWAY 



\section{PACIFIC JOURNAL OF MATHEMATICS}

\section{EDITORS}

RICHARD ARENS (Managing Editor)

University of California

Los Angeles, California 90024

R. A. BeAumont

University of Washington

Seattle, Washington 98105
J. DugundJI*

Department of Mathematics

University of Southern California

Los Angeles, California 90007

D. Gilbarg and J. Milgram

Stanford University

Stanford, California 94305

\section{ASSOCIATE EDITORS}

E. F. BECKENBACH

B. H. NEUMANN

F. WOLF

K. YoSHIDA

\section{SUPPORTING INSTITUTIONS}

UNIVERSITY OF BRITISH COLUMBIA
CALIFORNIA INSTITUTE OF TECHNOLOGY
UNIVERSITY OF CALIFORNIA
MONTANA STATE UNIVERSITY
UNIVERSITY OF NEVADA
NEW MEXICO STATE UNIVERSITY
OREGON STATE UNIVERSITY
UNIVERSITY OF OREGON
OSAKA UNIVERSITY

UNIVERSITY OF BRITISH COLUMBIA CALIFORNIA INSTITUTE OF TECHNOLOGY UNIVERSITY OF CALIFORNIA MONTANA STATE UNIVERSITY NEW MEXICO STATE UNIVERSITY UNIVERSITY OF OREGON OSAKA UNIVERSITY
UNIVERSITY OF SOUTHERN CALIFORNIA STANFORD UNIVERSITY UNIVERSITY OF TOKYO UNIVERSITY OF UTAH WASHINGTON STATE UNIVERSITY UNIVERSITY OF WASHINGTON AMERICAN MATHEMATICAL SOCIETY NAVAL WEAPONS CENTER

* C. R. DePrima California Institute of Technology, Pasadena, CA 91109, will replace J. Dugundji until August 1974. 


\section{Pacific Journal of Mathematics}

\section{Vol. 51, No. $1 \quad$ November, 1974}

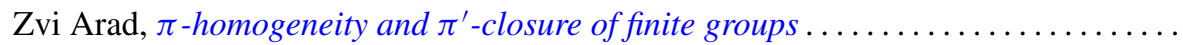

Ivan Baggs, A connected Hausdorff space which is not contained in a maximal

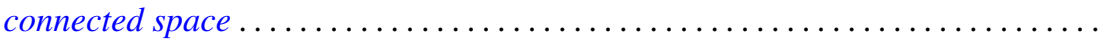

Eric Bedford, The Dirichlet problem for some overdetermined systems on the unit ball in $C^{n}$

R. H. Bing, Woodrow Wilson Bledsoe and R. Daniel Mauldin, Sets generated by

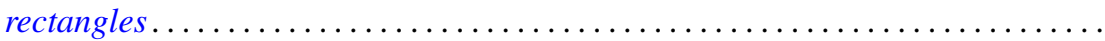

Carlo Cecchini and Alessandro Figà-Talamanca, Projections of uniqueness for

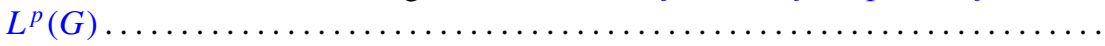

Gokulananda Das and Ram N. Mohapatra, The non absolute Nörlund summability of Fourier series .

Frank Rimi DeMeyer, On separable polynomials over a commutative ring ........ Richard Detmer, Sets which are tame in arcs in $E^{3} \ldots \ldots \ldots \ldots \ldots \ldots \ldots \ldots$

William Erb Dietrich, Ideals in convolution algebras on Abelian groups ..........

Bryce L. Elkins, A Galois theory for linear topological rings .................

William Alan Feldman, A characterization of the topology of compact convergence on $C(X)$.

Hillel Halkin Gershenson, A problem in compact Lie groups and framed cobordism

Samuel R. Gordon, Associators in simple algebras.

Marvin J. Greenberg, Strictly local solutions of Diophantine equations

Jon Craig Helton, Product integrals and inverses in normed rings . . . . . . . . . . . .

Domingo Antonio Herrero, Inner functions under uniform topology . . .

Jerry Alan Johnson, Lipschitz spaces .

Marvin Stanford Keener, Oscillatory solutions and multi-point boundary value

functions for certain nth-order linear ordinary differential equations.

John Cronan Kieffer, A simple proof of the Moy-Perez generalization of the

Shannon-McMillan theorem .......................

Joong Ho Kim, Power invariant rings

Gangaram S. Ladde and V. Lakshmikantham, On flow-invariant sets .

Roger T. Lewis, Oscillation and nonoscillation criteria for some self-adjoint even

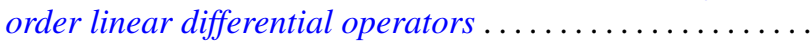

Jürg Thomas Marti, On the existence of support points of solid convex sets ..

John Rowlay Martin, Determining knot types from diagrams of knots . .

James Jerome Metzger, Local ideals in a topological algebra of entire functions

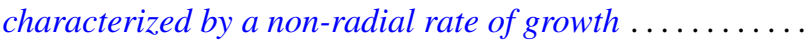

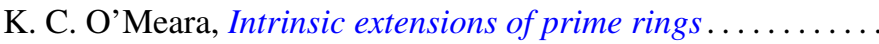

Stanley Poreda, A note on the continuity of best polynomial approximations ..

Robert John Sacker, Asymptotic approach to periodic orbits and local prolongations

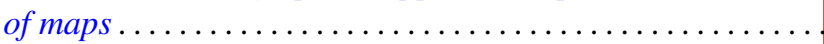

Eric Peter Smith, The Garabedian function of an arbitrary compact set . .

Arne Stray, Pointwise bounded approximation by functions satisfying a side condition

John St. Clair Werth, Jr., Maximal pure subgroups of torsion complete abelian

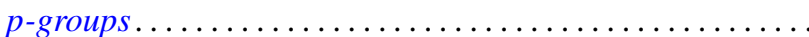

